\title{
Changes in retinal light sensitivity following blunt ocular trauma
}

\begin{abstract}
Purpose To prospectively examine changes in retinal light sensitivity following blunt ocular trauma in eyes with traumatic hyphaema with no evidence of retinal injuries 1 week, 1 month and 4 months after injury.

Method Sixteen patients who sustained hyphaema after blunt ocular trauma without visible traumatic retinal lesions underwent visual field testing on the $\mathrm{C} 30-2$ programme of the Humphrey field analyser as soon as visual acuity recovered to 0.7 or more with correction. Results Significant reduction in retinal sensitivity with MD (mean deviation) $p$ values less than $5 \%$ was found in $50 \%$ (8 eyes) of our patients 1 week after injury. MD $p$ values significantly improved 1 month after injury $(p<0.001)$ and even more so after 4 months $(p<0.00004)$. After 4 months only in one eye $(6 \%)$ was a significant reduction in retinal sensitivity observed with a MD $p$ value less than $5 \%$. No correlations between improvement in retinal sensitivity and the extent of hyphaema or the extent of angle recession were observed.

Conclusions In $50 \%$ of eyes following blunt ocular trauma without evident traumatic posterior segment abnormalities significant transient reduction in retinal light sensitivity was observed with nearly complete recovery over time.
\end{abstract}

Key words Angle recession, Automated static perimetry, Blunt ocular trauma, Hyphaema, Retinal light sensitivity, Visual field

Blunt ocular trauma results in various types of anterior and posterior segment changes. ${ }^{1-10}$ The anterior segment of the eye is particularly vulnerable. The iris, filtration angle, lens and zonule are the most affected parts in this segment. Hyphaema and traumatic angle recession are the potential sight-threatening consequences of blunt ocular trauma. ${ }^{11-16} \mathrm{An}$ elevation of intraocular pressure is often seen immediately after blunt ocular trauma. The risk of secondary glaucoma after contusion of the eye is low. ${ }^{17}$ In the posterior segment, blunt ocular trauma may cause damage to the retina (commotio retinae), retinal epithelium (retinal pigment epithelium oedema), choroid (choroid rupture) and optic nerve (optic nerve avulsion) alone or in combination. Traumatic retinal holes, retinal detachment or dialysis, vitreous haemorrhage and arterial occlusion may also occur after blunt ocular trauma. ${ }^{18-21}$ Retinal opacity is one of the most characteristic lesions. ${ }^{22}$ The major site of injury in commotio retinae seems to be at the level of the photoreceptor outer segment/retinal pigment epithelium junction..$^{20,21,23,24}$ The degree of sensory retina and pigment epithelium damage caused by the trauma is responsible for the prognosis of traumatic retinopathy. ${ }^{23-28}$ In one study loss of contrast sensitivity following blunt ocular trauma was found. The more severe the structural abnormalities of the eye, the more marked was the difference in contrast sensitivity between normal and injured eyes. ${ }^{29}$

Retinal light sensitivity is an important measurable parameter of visual function. The introduction of automated static perimetry has provided a new approach to the study of retinal function. Neuron loss may be detected at an earlier stage, which was not possible with manual perimetry. ${ }^{30-33}$ The presence, nature and the extent of retinal light sensitivity reduction following blunt ocular trauma were examined using automated static perimetry to detect visual field changes in our patients with no evidence of retinal changes.

The aim of the present study was to examine prospectively how retinal light sensitivity is affected by blunt trauma in eyes with traumatic hyphaema. As visual field defects have been demonstrated as early as 1 week after injury, our purpose was to assess any additional changes in retinal sensitivity during a period of 4 months after injury, as well as to determine whether there is a correlation between visual field loss and age of the patient, extent of hyphaema or extent of traumatic angle recession.
Dušica Pahor, MD, PhD Department of Ophthalmology Teaching Hospital Maribor Ljubljanska 5 2000 Maribor, Slovenia Tel: +38662321100

Received: 6 September 1999 Accepted in revised form: 25 February 2000 


\section{Methods}

Sixteen eyes of 16 patients (all male) with traumatic hyphaema following contusional eye injury of sufficient severity to necessitate hospital admission were included in our study during a period of 1 year. Patients with the following criteria were excluded from the study: no complete resorption of hyphaema within 1 week after injury, secondary haemorrhage-rebleeding, vitreous haemorrhage, various lesions in the posterior pole and periphery of the fundus, visual acuity less than 0.7 . Patients who had diseases known to affect the visual field, including aphakia, cataract, glaucoma or any other diseases affecting the optic nerve or macula, were also excluded. The exclusion criteria also included a history of head trauma to exclude possible occipital lobe damage and the influence of this on the visual field. All patients included in the study had suffered only blunt ocular trauma. The most frequent causes were contusion with a ball (4 of 16 patients, $25 \%$ ), snowball ( 2 of $16,12.5 \%$ ), stone $(2$ of $16,12.5 \%)$ or a piece of wood ( 2 of $16,12.5 \%)$.

The patients underwent a complete ophthalmological examination, including visual acuity, slit-lamp examination, tonometry and ophthalmoscopy. Visual acuity was 0.7 or better in all patients. Except for signs of traumatic hyphaema, which resolved in a few days, and traumatic angle recession, the ophthalmological examination was normal in all patients. Hyphaema and traumatic angle recession were determined by slit-lamp biomicroscopy and gonioscopy.

Automated visual field charting using threshold programme C 30-2 of the Humphrey field analyser was performed 1 week after injury on all these patients as soon as the hyphaema was completely resolved and visual acuity recovered to 0.7 or more. Visual field testing was performed in the fellow eye too for a control comparison of the learning curve. Visual acuity in these non-traumatised eyes was 0.8-1.0. The results with poor reliability as determined by fixation loss, and falsepositive and false-negative findings, were excluded from the statistical analysis. The Humphrey STATPAC analytical program was used to quantitatively evaluate each visual field. This program uses several global indices to compare the patient's visual sensitivity with the age-corrected sensitivity of 76 points in a $30^{\circ}$ field. For this study two of the global indices - mean deviation (MD) and corrected pattern standard deviation (CPSD) were used. MD is the average deviation or depression of the patient's overall field compared with the normal agecorrected reference field. A negative MD value indicates that sensitivity is depressed. CPSD is a measure of the degree to which the shape of the patient's hill of vision deviated from the normal age-corrected reference field after correction for the patient's intratest variability in response. Fixation was continually checked on the fixation monitor supplied on the Humphrey field analyser, which displays the eye on a video screen during perimetry. One month and 4 months after blunt ocular trauma the patients underwent the same procedure.

\section{Results}

The average age of our patients was 32.2 years $( \pm 18.4$; min. 10.0, max. 71). The average time of follow-up was 4.2 months (min. 4, max. 6).

Mild hyphaema (1-2 mm) was present in 5 eyes (31\%) and moderate hyphaema ( $2 \mathrm{~mm}$ to half the anterior chamber) in 11 eyes (69\%). Severe hyphaema (more than half the anterior chamber) was not observed in our patients.

Traumatic angle recession up to one quadrant was present in 5 eyes (31\%), up to two quadrants in 5 eyes (31\%), up to three quadrants in 1 eye $(6 \%)$ and up to four quadrants in 2 eyes (12\%). Three eyes (19\%) were without any anterior angle changes although they had mild hyphaema.

Traumatic posterior segment changes 1 week after injury at the time of visual field examination were not observed.

One week after injury obvious areas of reduced sensitivity in 8 of 16 eyes (50\%) were found. The MD of these 8 eyes had $p$ values of less than $5 \%$. In another 2 eyes $(12 \%)$ the MD $p$ values were equal to or greater than $10 \%$. The average MD value was $-3.4 \mathrm{db}$ ( \pm 1.6 ; min. -0.4 , max. -6.7$)$ (Fig. 1). In 3 eyes (19\%) CPSD $p$ values of less than $10 \%$ were found. CPSD $p$ values were greater than $10 \%$ in 13 eyes $(81 \%)$. The average CPSD value was $1.3 \mathrm{db}$ ( \pm 1.3 ; min. 0, max. 4.3).

One month after injury the MD $p$ values were less than $5 \%$ in only 2 eyes $(12 \%)$. The average MD value was $-2.1 \mathrm{db}( \pm 1.8 ;$ min. 0.7, max. -7.3 ) (Fig. 2). The improvement in MD values was significant $(p<0.001)$. The CPSD $p$ values were less than $10 \%$ in 2 eyes (12\%). The improvement was not significant $(p>0.05)$.

Four months after injury only in 1 eye $(6 \%)$ was a MD $p$ value less than $5 \%$ found. The average MD value was $-1.6 \mathrm{db}$ ( \pm 1.4; min. 0, max. -4.9) (Fig. 3). The improvement in MD value from 1 month after injury to 4 months after injury was statistically significant $(p<0.05)$.

When we compared the MD value at 1 week after injury with the MD value 4 months after injury the improvement was much more significant $(p<0.00004)$ (Table 1). CPSD $p$ values of less than $10 \%$ were found in 3 eyes (19\%). The improvement was not significant $(p>0.05)$.

Retinal sensitivities of the fellow eyes were normal in all patients. The average MD value was $-1.36 \mathrm{db}( \pm 0.80$; min. -2.66 , max. +0.02). A MD $p$ value less than $5 \%$ was not found. The average CPSD value was $0.97 \mathrm{db}( \pm 0.82$; min. 0.0, max. 2.27). A CPSD $p$ value less than $10 \%$ was also not found.

The degree of retinal light sensitivity reduction expressed in decibels at 1 week, 1 month and 4 months after blunt ocular trauma and the retinal sensitivity of the fellow eyes are presented in Table 2.

The relationships between each of the indices of visual field sensitivity (MD, CPSD) and age, extent of traumatic hyphaema and extent of traumatic angle recession were also evaluated because these factors were believed to be 
CEMTRAL 3 D - Z TIAESHMLDTEST

PAME K. F EIPTHDATE 23-10.3-52 DATE 18-1]3-94

STDWUS III, URITE, 0000031.5 RSB RINO SPOT CFEX SITE III

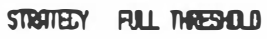

FIXATIOW TRPCET CONTR TIV 14:06:52

RX USED DS DOX DEC PUPIL DIFETER $5.0 \mathrm{~m}$ W 0.8

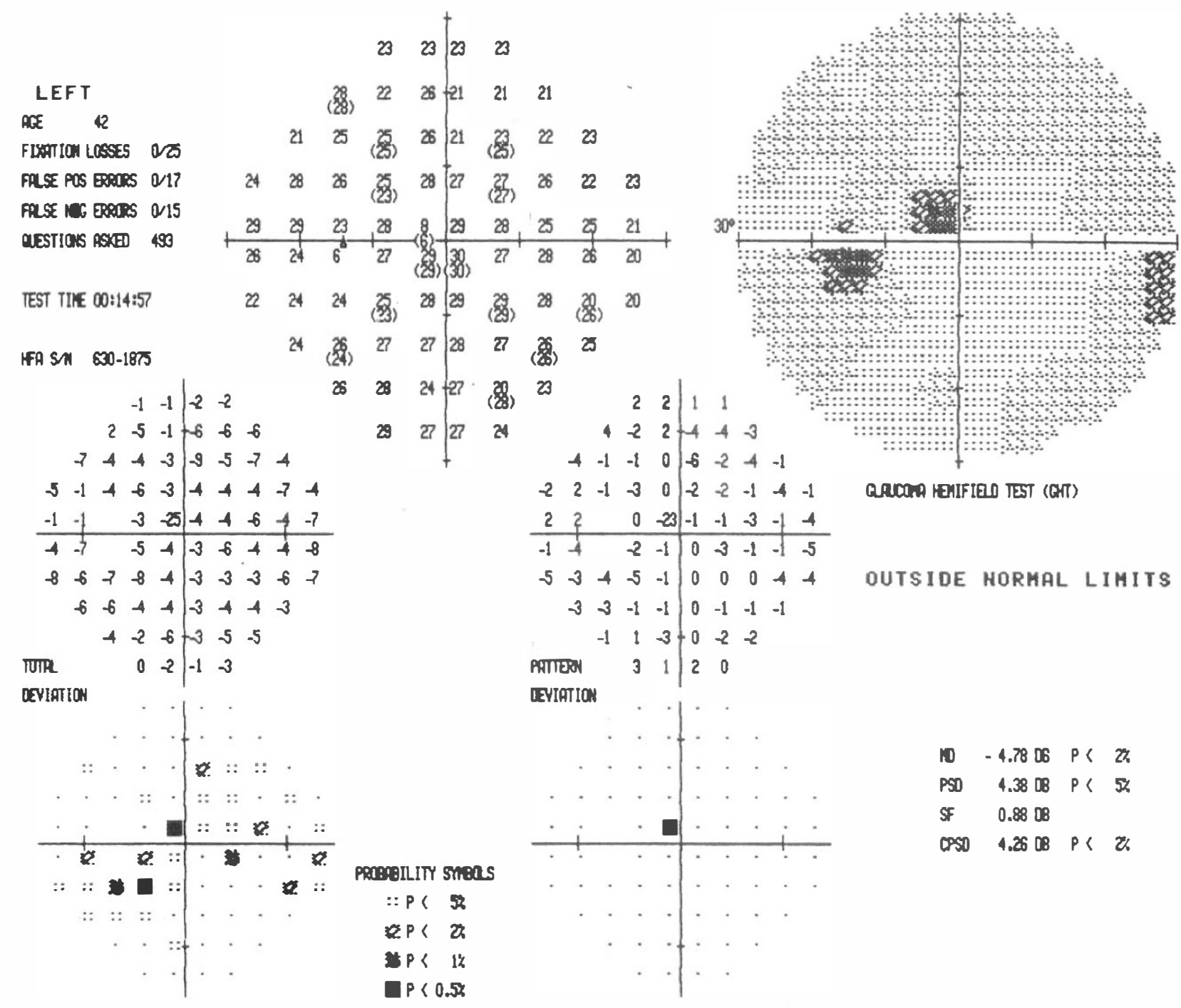

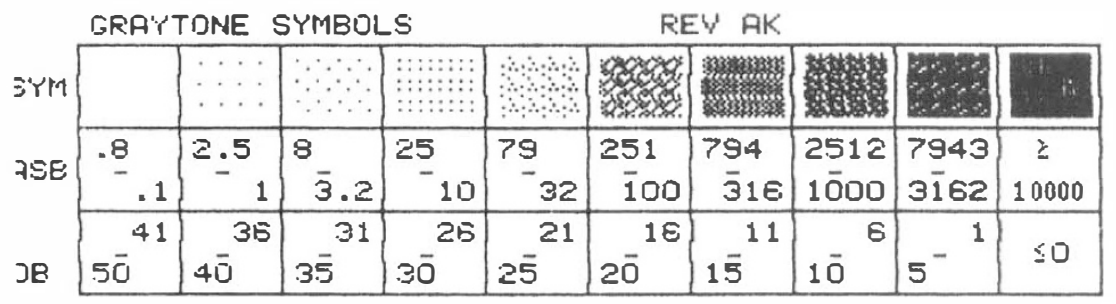

Fig. 1. Visual field defects 1 week after blunt ocular trauma.

related to the reduction in retinal light sensitivity after blunt ocular trauma without evident fundus changes. No statistically significant positive correlation was observed in any case $(p>0.10)$. The improvement in retinal sensitivity during the 4 months after injury also was not associated with age, extent of hyphaema or the extent of angle recession $(p>0.05)$.

\section{Discussion}

Many studies have demonstrated anterior and posterior segment abnormalities following blunt ocular trauma. ${ }^{1-10}$ The injured eye must be examined very carefully, both the anterior and posterior segments. Biomicroscopy and gonioscopy are the most important methods for anterior segment examination. 


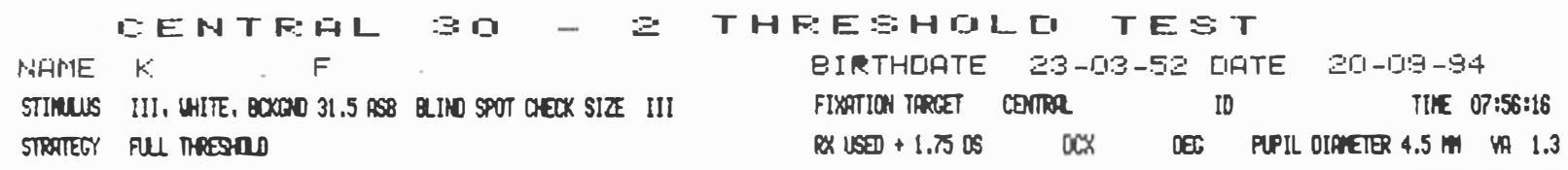

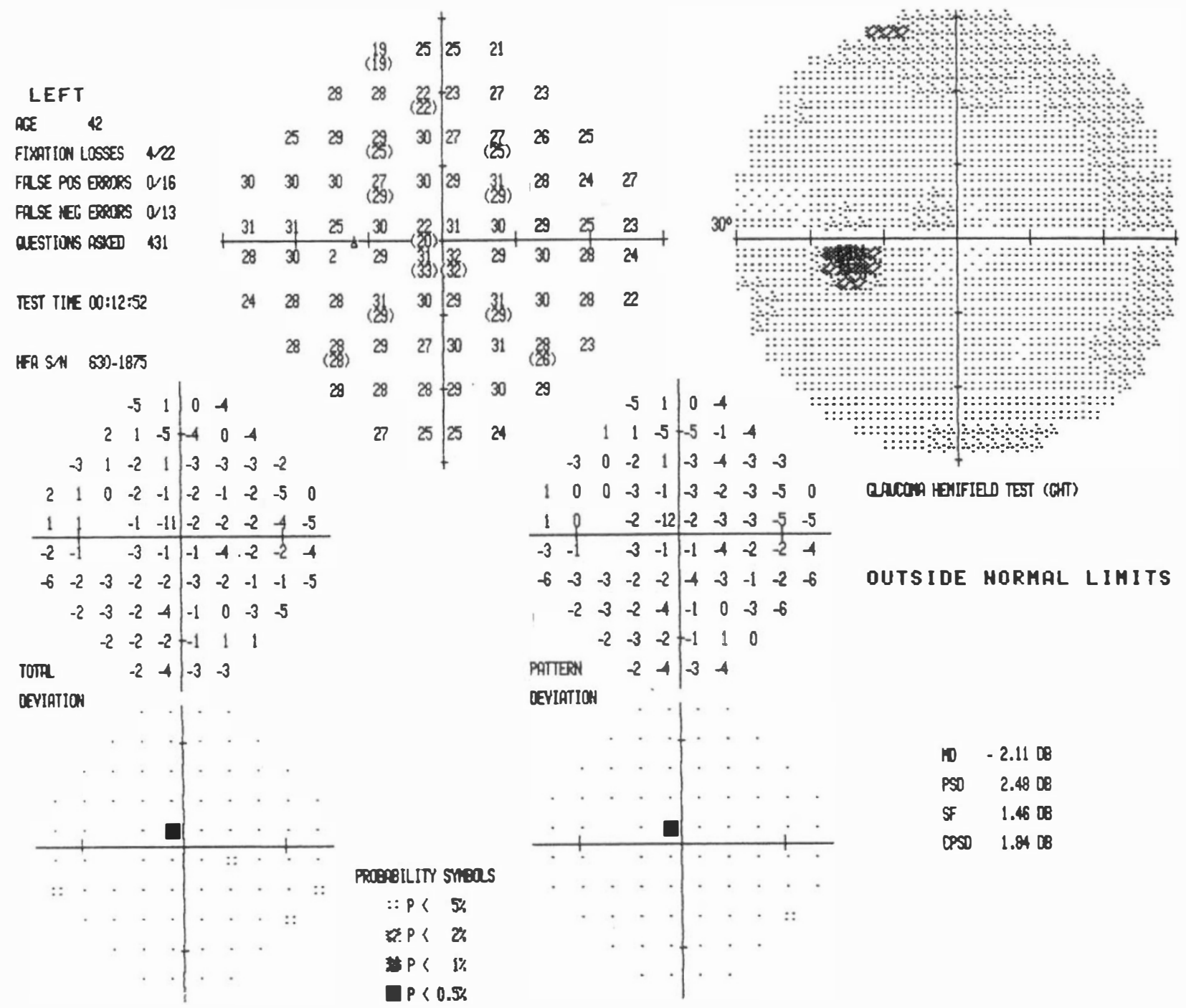

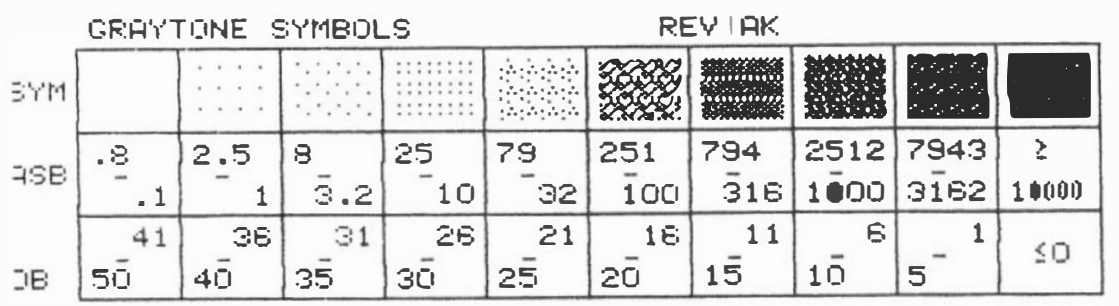

Fig. 2. Visual field defects 1 month after blunt ocular trauma.

In the current study, a significant reduction in overall sensitivity in the visual field was noted in eyes with traumatic hyphaema following blunt ocular trauma without evident posterior segment abnormalities. Visual field defects were noted in $50 \%$ (8 of 16) of the injured eyes 1 week after trauma with complete resorption of hyphaema. The current results indicate that there is a significant reduction in sensitivity in the visual field in eyes with traumatic anterior segment consequences.
Furthermore, the results indicate that visual field defects may occur in injured eyes without clinically detectable post-traumatic retinopathy. Visual field defects can be detected prior to visible retinal damage. Half our patients had significantly reduced retinal sensitivity despite a normal fundus appearance.

The quantitative nature of the data obtained with the automated technique facilitated a statistical analysis of the results which would not have been possible with 


\begin{tabular}{|c|c|c|c|c|c|c|c|}
\hline NAIAIE & $k$ & & & BIRTHLÄTE & $23-10.3-52$ & DATE & $20-1 己-34$ \\
\hline STIMUS & III, LHITE, BCKCOO 31.5 ASB & BIND SPOT CEEK SILE & III & FIXATION TRRERT & COIRR & ID & TIE $07: 47: 59$ \\
\hline STRATECY & RU TRESHOD & & & RXX USED + 1.75 DS & $00 x$ & PUPIL & OIAETER 4.5 WI 1.3 \\
\hline
\end{tabular}
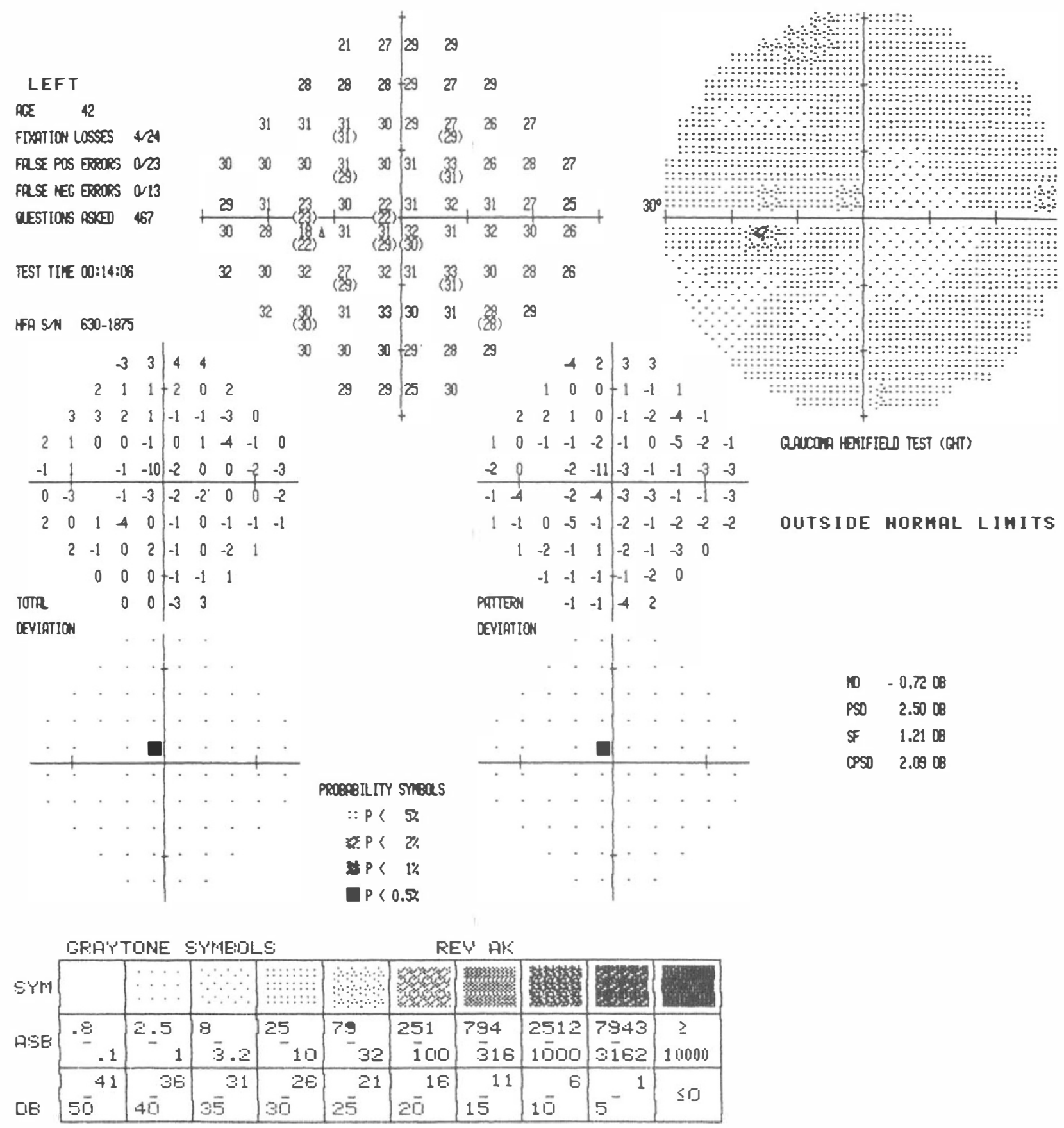

Fig. 3. Visual field defects 4 months after blunt ocular trauma.

Goldmann perimetry. The mean deviation (MD) examines the average difference across all points in the visual field and is therefore most sensitive for detecting visual field defects. ${ }^{30-33}$ No correlation between age, extent of hyphaema or the extent of angle recession and visual field defects was evident in our patients. We expected extensive visual field loss in eyes with severe traumatic anterior segment abnormalities such as more pronounced hyphaema or angle recession. Our results did not confirm these expectations.
The results of this study further suggest that in the course of time the magnitude of the sensitivity reduction will diminish. One month after injury a significant reduction in retinal light sensitivity was observed in only

Table 1. The improvement in $M D$ (mean deviation)

\begin{tabular}{lll}
\hline Time interval after injury & \multicolumn{1}{c}{ MD $(\mathrm{db})$} & $p$ value \\
\hline 1 week & $-3.4( \pm 1.6)$ & - \\
1 month & $-2.1( \pm 1.8)$ & $<0.001$ \\
4 months & $-1.6(+1.4)$ & $<0.00004$ \\
\hline
\end{tabular}


Table 2. Retinal light sensitivity in the traumatised eye 1 week, 1 month and 4 months after blunt ocular trauma compared with the fellow eye in our patients

\begin{tabular}{|c|c|c|c|c|c|c|c|c|}
\hline \multirow[b]{3}{*}{ Patient no. } & & & \multicolumn{6}{|c|}{ Traumatised eye } \\
\hline & \multicolumn{2}{|c|}{ Fellow eye } & \multicolumn{2}{|c|}{1 week } & \multicolumn{2}{|c|}{1 month } & \multicolumn{2}{|c|}{4 months } \\
\hline & MD & CPSD & MD & CPSD & MD & CPSD & MD & CPSD \\
\hline 1 & -0.56 & 2.00 & -4.78 & 4.26 & -2.11 & 1.84 & -0.72 & 2.00 \\
\hline 2 & -2.00 & 0.00 & -6.10 & 0.00 & -7.33 & 5.60 & -4.98 & 2.96 \\
\hline 3 & -1.72 & 1.09 & -1.96 & 0.00 & -2.00 & 0.00 & -1.02 & 1.15 \\
\hline 4 & -1.50 & 0.00 & -6.67 & 0.35 & -2.66 & 2.27 & -2.16 & 2.54 \\
\hline 5 & -2.66 & 2.27 & -5.22 & 1.61 & -4.3 & 0.00 & -4.00 & 0.00 \\
\hline 6 & -1.96 & 0.00 & -4.05 & 2.93 & -2.31 & 1.67 & -2.33 & 3.25 \\
\hline 7 & -0.39 & 0.87 & -2.83 & 0.78 & +0.69 & 1.01 & -1.05 & 0.00 \\
\hline 8 & -2.40 & 2.20 & -2.99 & 1.06 & -2.18 & 1.57 & -1.72 & 1.09 \\
\hline 9 & -0.89 & 0.00 & -2.84 & 0.48 & -0.34 & 0.87 & -0.30 & 0.00 \\
\hline 10 & -1.27 & 1.18 & -3.62 & 1.47 & -1.58 & 2.25 & -1.00 & 0.40 \\
\hline 11 & -1.04 & 1.20 & -0.44 & 0.00 & -0.02 & 1.50 & +0.00 & 1.00 \\
\hline 12 & -2.18 & 1.57 & -3.68 & 3.24 & -2.40 & 3.17 & -3.16 & 3.92 \\
\hline 13 & +0.02 & 1.50 & -1.91 & 1.18 & -1.81 & 1.28 & -0.89 & 0.00 \\
\hline 14 & -1.91 & 1.18 & -3.28 & 1.96 & -1.72 & 1.25 & -1.27 & 1.18 \\
\hline 15 & -1.00 & 0.40 & -2.13 & 1.04 & -1.12 & 0.91 & -1.04 & 1.20 \\
\hline 16 & -0.33 & 0.00 & -2.26 & 0.24 & -1.81 & 0.80 & -0.33 & 0.00 \\
\hline
\end{tabular}

$\mathrm{MD}$, mean deviation; CPSD, corrected pattern standard deviation.

$12 \%$ (2 of 16$)$ and after 4 months in only $6 \%(1$ of 16$)$ of the injured eyes. Most of the injured eyes had normal retinal sensitivity 4 months after blunt ocular trauma. We hypothesise that visual field defects may be primarily the result of traumatic vascular compromise, which is a transitional state. The pathogenesis of commotio retinae in animal models included extracellular oedema and photoreceptor outer segment disruption. In the human eye with clinically observed commotio retinae photoreceptor outer segment disruption and damage to the retinal pigment epithelium were revealed. ${ }^{20,21}$ Damage to the choriocapillaris occurred at an early stage after trauma. ${ }^{25}$ In severe cases, delayed filling of the choroidal arteries and changes in the choroidal vasculature occurred together with impairment of the choriocapillaris; therefore severe traumatic choroid involvement can cause intense ischaemic changes in the outer retinal layer. ${ }^{25}$ In our patients no retinal oedema was observed. Thus traumatic visual field loss in eyes without evident posterior segment abnormalities could be primarily the result of a temporary effect on the retinal circulation. It remains unclear whether the visual field loss in traumatic eyes represents a stage of localised regions of defective capillary circulation which recover over time. Visual field defects were not permanent and after 4 months had practically disappeared.

Unfortunately fluorescein or indocyanine green angiography was not performed in our patients immediately after injury to confirm our conclusions. To our knowledge, this study is the first to separately assess and compare retinal sensitivity over time using static perimetry in eyes following blunt ocular trauma. A further prospective study with a larger number of patients with retinal angiography is necessary to confirm our results.
In conclusion, in $50 \%$ of eyes following blunt ocular trauma without evident traumatic posterior segment abnormalities a significant transient reduction in retinal light sensitivity was observed with nearly complete recovery over time.

\section{References}

1. Zagelbaum BM, Tostanoski JR, Kremer DJ, Hursh PS. Urban eye trauma: a one-year prospective study. Ophthalmology 1993;100:851-6.

2. Dietrich TM, Kleinschmidt R, Meyer HJ. Veränderte Ursachen und Folgen schwerer Augenverletzungen. Klin Monatsbl Augenheilkd 1992;201:216-20.

3. Kahle G, Dach TH, Wollensak J. Augenverletzungen beim Squash. Klin Monatsbl Augenheilkd 1993;203:195-9.

4. Gregory PTS. Sussex Eye Hospital sports injuries. Br J Ophthalmol 1986;70:748-50.

5. Canavan YM, O'Flaherty MJ, Archer DB, Elwood JH. A 10year survey of eye injuries in Northern Ireland, 1967-76. Br J Ophthalmol 1980;64:618-25.

6. Macewen CJ. Eye injuries: a prospective survey of 5671 cases. Br J Ophthalmol 1989;73:888-94.

7. Macewen CJ. Sport associated eye injuries: a casualty department survey. Br J Ophthalmol 1987;71:701-5.

8. Kreutzen PH. Verletzungsfolgen nach Augenprellungen: Ergebnisse einer Studie über 313 Fälle. Klin Monatsbl Augenheilkd 1983;182:206-9.

9. Kroll P, Stoll W, Kirchhoff E. Kontusions-Sog-Trauma nach Ballverletzungen. Klin Monatsbl Augenheilkd 1983;182:555-9.

10. Schütten G, Reim M. Augenverletzungen durch Brillengläser. Klin Monatsbl Augenheilkd 1987;191:237-9.

11. Farber MD, Fiscella R, Goldberg MF. Aminocaproic acid versus prednisone for the treatment of traumatic hyphema. Ophthalmology 1991;98:279-86.

12. Ng CS, Sparrow JM, Strong NP, Rosenthal AR. Factors related to the final visual outcome of 425 patients with traumatic hyphema. Eye 1992;5:305-7.

13. Canavan YM, Archer DB. Anterior segment consequences of blunt ocular injury. Br J Ophthalmol 1982;66:549-55. 
14. Pahor D, Gračner B. Visual field loss following blunt ocular trauma. Ophthalmologica 1998;212:43-5.

15. Pahor D, Gračner B. Veränderungen der Lichtunterschiedsempfindlichkeit der Netzhaut nach stumpfem Bulbustrauma. Spectrum Augenheilkd 1998;12:243-7.

16. Gračner B, Kurelac Z. Gonioscopische Veränderungen durch stumpfe Augapfelverletzungen beim Sport. Klin Monatsbl Augenheilkd 1985;186:128-30.

17. Zenker HJ. Augeninnendruckverhalten nach Bulbusprellungen. Ophthalmologe 1993;90:631-4.

18. Atmaca LS, Vilmaz M. Changes in the fundus caused by blunt ocular trauma. Ann Ophthalmol 1993;25:447-52.

19. Williams DF, Mieler WF, Williams GA. Posterior segment manifestation of ocular trauma. Retina 1990;10(Suppl1):S35-44.

20. Mansour AM, Green WR, Hogge C. Histopathology of commotio retinae. Retina 1992;12:24-8.

21. Blight R, Dean Hart JC. Structural changes in the outer retinal layers following blunt mechanical non-perforating trauma to the globe: an experimental study. Br J Ophthalmol 1977;61:573-87.

22. Berlin RZ. Zur sogennanten commotio retinae. Klin Monatsbl Augenheilkd 1973;11:42-78.

23. Hart JCD, Frank HJ. Retinal opacification after blunt nonperforating concussional injuries to the globe: a clinical and retinal fluorescein angiographic study. Trans Ophthalmol Soc UK 1975;95:94-100.
24. Yamana T. Retinochoroidal lesions in concussional injuries of the eyes: an experimental study. Acta Soc Ophthalmol Jpn 1981;90:1049-66.

25. Kohno T, Miki T, Hayashi K. Choroidopathy after blunt trauma to the eye: a fluorescein and indocyanine green angiographic study. Am J Ophthalmol 1998;126:248-60.

26. Liem ATA, Keunen JEE, Norren DV. Reversible cone photoreceptor injury in commotio retinae of the macula. Retina 1995;15:58-61.

27. Mansour AM, Green WR, Hogge C. Histopathology of commotio retinae. Retina 1992;12:24-8.

28. Sipperley MJO, Quigley HA, Gass JDM. Traumatic retinopathy in primates: the explanation of commotio retinae. Arch Ophthalmol 1978;96:2267-73.

29. Canavan Y, Archer DB. Loss of contrast sensitivity following contusional eye injury. Br J Ophthalmol 1980;64:613-7.

30. Statpac Users Guide. San Leandro, CA: Allergan Humphrey, 1986.

31. Anderson DR. Automatic static perimetry. St Louis: MosbyYear Book, 1992.

32. Stewart WC. Avoiding mistakes in interpreting visual fields. I. Basic concepts. Clin Signs Ophthalmol 1993;14:2-15.

33. Stewart WC. Avoiding mistakes in interpreting visual fields. II. Evaluating the printout. Clin Signs Ophthalmol 1993;14:2-15. 